\title{
Analysis of Cardiac Symptoms Preceding Cardiac Arrest
}

\author{
SIDNEY GOLDSTEIN, MD, SHARON VANDERBRUG MEDENDORP, MPH, \\ J. RICHARD LANDIS, PhD, ROBERT A. WOLFE, PhD, RICHARD LEIGHTON, MD, \\ GEORGE RITTER, MD, C. MARK VASU, MD, and ALLYN ACHESON, BA
}

\begin{abstract}
Prodromal symptoms and cardiac history were examined in 227 patients with coronary artery disease who were successfully resuscitated after out-of-hospital cardiac arrest. Cardiac arrest was suddenwith either no symptoms or symptoms for less than 1 hour-in $71 \%$ of the patients. Nonsudden death-death occurring after more than 1 hour of symptoms-occurred in $29 \%$ of the patients. A history of cardiovascular disease was present in $85 \%$
\end{abstract}

of patients with sudden cardiac arrest and in $83 \%$ with nonsudden arrest. Cardiac arrest occurred without symptoms in $38 \%$ of the patients with sudden cardiac arrest and was the first expression of coronary artery disease in $4 \%$ of the entire study group. This study indicates that cardiac arrest usually occurs with symptoms and almost always in the setting of a history of cardiovascular disease.

(Am J Cardiol 1986;58:1195-1198)
$\mathbf{T}$ he instantaneous nature of sudden cardiac death has been appreciated for centuries and has been supported by a number of anecdotal and epidemiologic reports. Although death often occurs instantaneously, it usually occurs in the setting of cardiovascular disease. ${ }^{1-5}$ The fact that cardiac arrest usually occurs as an outcome of previous cardiac disease is important in determining medical strategies for prevention of sudden death. Because of this, therapy directed at the treatment of known cardiovascular disease can modify the incidence of sudden death.

Although recent studies indicate that both ischemia $^{6}$ and infarction ${ }^{7}$ can occur silently without recognized symptoms, the frequency of sudden death without symptoms is not well known. Knowledge about the prodromal symptoms occurring before cardiac arrest can provide insight into the mechanism of the event. It is obviously difficult to ascertain the prodromal symp-

From the Henry Ford Heart and Vascular Institute and the Division of Cardiovascular Medicine, Department of Medicine, Henry Ford Hospital, Detroit, and Department of Biostatistics, University of Michigan, Ann Arbor, Michigan. This study was supported by grants HI.188000-09 from the National Heart, Lung, and Blood Institute, Bethesda, Maryland, and the FMS Foundation of Grand Rapids, Michigan. Manuscript received May 1, 1986; revised manuscript received July 21, 1986, accepted July $22,1986$.

Address for reprints: Sidney Goldstein, MD, Henry Ford Hospital, Division of Cardiovascular Medicine, 2799 West Grand Boulevard, Detroit, Michigan 48202. toms experienced by cardiac arrest victims because the patients are rarely available for interview. Patients resuscitated after out-of-hospital cardiac arrest, however, are a unique group in whom the symptoms and suddenness of cardiac arrest can be explored. To investigate these issues, we interviewed patients resuscitated after an out-of-hospital cardiac arrest with regard to their prodromal symptoms and medical history.

\section{Methods}

All emergency cardiac arrest runs of the emergency medical services and all successfully resuscitated cardiac arrest victims in Lucas County, Ohio (pop. 484,370 ), Kent County, Michigan (pop. 411,044), and Southfield, Michigan (pop 69,285) from July 1, 1975, through June 30,1982 , were registered in the study. We have described the characteristics of the emergency care systems in these communities. ${ }^{1}$ During the 84 months of this study a total of 3,849 cardiac arrest events occurred. Two hundred seventy-four patients $(7 \%)$ left the primary receiving hospital alive and are considered to have had successful resuscitations. While in the hospital, these patients were registered and laboratory and electrocardiographic data were collected. Hospital records were reviewed for clinical information relating to medical history.

The demographic characteristics and methods of patient classification have been discussed previously. ${ }^{1}$ Of the 274 patients successfully resuscitated, 227 (83\%) were classified as having significant $\mathrm{CAD}$ and are the 
TABLE I Clinical Characteristics of Sudden and Nonsudden Arrest in 227 Resuscitated Victims of Out-of-Hospital Cardiac Arrest with Coronary Artery Disease

\begin{tabular}{lcc} 
& $\begin{array}{c}\text { Sudden } \\
(\mathrm{n}=162)\end{array}$ & $\begin{array}{c}\text { Nonsudden } \\
(\mathrm{n}=65)\end{array}$ \\
\hline Medical history (\%) & 54 & 65 \\
$\quad$ Angina pectoris & 52 & 42 \\
Systemic hypertension & 52 & 42 \\
Previous myocardial infarction & 35 & 38 \\
Heart failure & 15 & 17 \\
None of above & & \\
Prodromal symptoms (\%) & 33 & 72 \\
Chest pain & 26 & 48 \\
Dyspnea" & 13 & 22 \\
Indigestion & 19 & 23 \\
Lightheadedness & 13 & 14 \\
Syncope & 38 & 0 \\
None of above & 5 & 0 \\
No symptoms and no history & & \\
\hline
\end{tabular}

$\cdot p<0.05$

population analyzed in this study. All other patients, without evidence of CAD, were excluded from further data analysis. Using previously described criteria, ${ }^{1} 91$ $(40 \%)$ were classified as having had an acute myocardial infarction, $88(37 \%)$ an ischemic event and 48 $(18 \%)$ a primary arrhythmic event. The presence of preexisting cardiovascular disease including angina pectoris, myocardial infarction, congestive heart failure, systemic hypertension and diabetes mellitus was identified. In addition to the laboratory and electrocardiographic data, patients were interviewed and questioned about the duration and nature of symptoms before arrest. Interviews were carried out by nurse clinicians at each study center using a standardized questionnaire. Patients were interviewed as soon as possible after the event.

An extensive database involving several hundred variables for each patient has been created, edited and stored in the disk files at the University of Michigan Computing Center. These data were analyzed within the Michigan Interactive Data Analysis System (MIDAS). Subgroup comparisons for differences in preva-

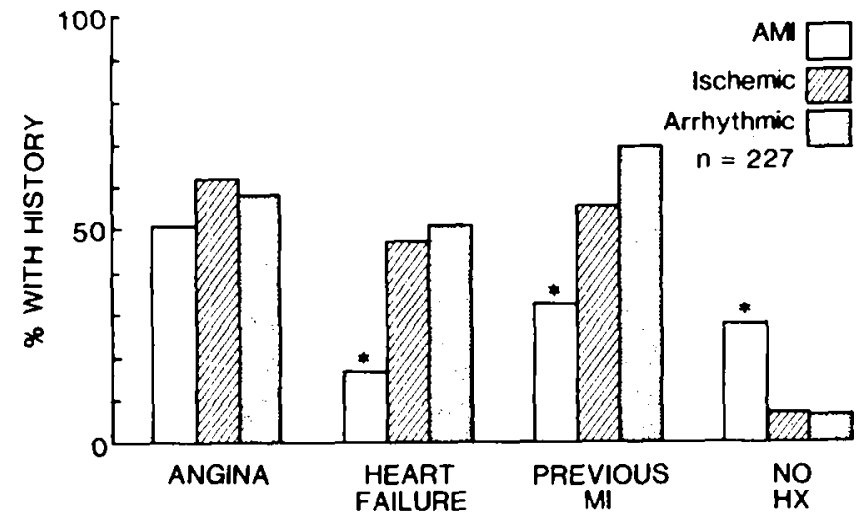

FIGURE 1. Relation of cardiac history to clinical arrest event. AMI = acute myocardial infarction. $p<0.05$, AMI vs ischemic and arrhythmic event.
TABLE II Characteristics of Sudden and Nonsudden Arrest in 227 Resuscitated Victims of Out-of-Hospital Cardiac Arrest with Coronary Artery Disease-Entry Event Related to Suddenness of Arrest

\begin{tabular}{|c|c|c|c|}
\hline Entry Event $\dagger$ & $n$ & $\begin{array}{c}\text { Sudden }(n=162) \\
(\%)\end{array}$ & $\begin{array}{c}\text { Nonsudden }(n=65) \\
(\%)\end{array}$ \\
\hline $\begin{array}{l}\text { Acute myocardial } \\
\text { infarction }\end{array}$ & 91 & 63 & 37 \\
\hline Ischemic events* & 88 & 80 & 20 \\
\hline Primary arrhythmias ${ }^{\circ}$ & 48 & 73 & 27 \\
\hline
\end{tabular}

lences were tested using the standard Pearson chisquare statistics. Cumulative survival curves were plotted using the Kaplan-Meier survival analysis.

\section{Results}

Patients were classified as having a sudden cardiac arrest if they had no symptoms or if their symptoms preceded the arrest for less than 1 hour. If symptoms preceded arrest by more than 1 hour, they were classified as a nonsudden arrest. Of the 227 resuscitated patients, $162(71 \%)$ had sudden cardiac arrests and 65 $(29 \%$ ] nonsudden cardiac arrests (Table I). A history of angina pectoris, heart failure or myocardial infarction together with a history of systemic hypertension was defined as a history of cardiac disease. This history was found in $85 \%$ of the sudden and $83 \%$ of the nonsudden cardiac arrest victims.

Chest pain was the most common prodromal symptom in both the sudden and nonsudden arrest groups, but was significantly more common in the nonsudden arrest group (Table I). The incidence of dyspnea in the nonsudden cardiac arrest group was almost twice that in the sudden cardiac arrest group. In the sudden cardiac arrest group, arrest occurred without previous symptoms in $38 \%$ (61 of 162) and in the absence of both history and symptoms in 5\% (8 of 162). By definition, the nonsudden arrest group were all symptomatic before the event. For the entire group of 227 patients, cardiac arrest occurred in $26 \%$ without symptoms and in $4 \%$ without either a history of cardiac disease or symptoms.

In Table II the suddenness of cardiac arrest is related to the clinical event associated with the cardiac arrest event. Patients whose arrest event was an acute myocardial infarction tended to have symptoms and had nonsudden arrest more frequently than patients in the ischemic and primary arrhythmic groups.

The relation of the historical components of cardiovascular disease before cardiac arrest to the clinical arrest event itself is shown in Figure 1. Angina pectoris was the most common. A history of heart failure, hypertension and previous myocardial infarction was more frequent in patients arresting with an ischemic $(47 \%, 56 \%$ and $57 \%)$ or primary arrhythmic event $(51 \%, 58 \%$ and $71 \%)$ than those who had an acute myocardial infarction $(16 \%, 37 \%$ and $33 \%$ ) (p <0.05). Cardiac arrest was the first historical presentation of 
TABLE III Relation of History to Clinical Arrest Event

\begin{tabular}{lccc}
\hline & $\begin{array}{c}\text { Acute Myocardial } \\
\text { Infarction } \\
(n=91)\end{array}$ & $\begin{array}{c}\text { Ischemic } \\
\text { Events } \\
(n-88)\end{array}$ & $\begin{array}{c}\text { Primary Arrhythmic } \\
\text { Events } \\
(n=48)\end{array}$ \\
\hline $\begin{array}{l}\text { Angina pectoris }(\%) \\
\text { Heart failure }(\%)\end{array}$ & 51 & 63 & 58 \\
Systemic hypertension $(\%)$ & 16 & 47 & 51 \\
Previous myocardial & 37 & 56 & 58 \\
$\quad$ infarction (\%) & 33 & 57 & 71 \\
No disease history (\%) & 29 & 7 & 8 \\
\hline
\end{tabular}

- $p<0.05$ acute myocardial infarction vs ischemic event and primary arrhythmic event.

heart disease in $29 \%$ of patients in the subgroup whose arrest was associated with acute myocardial infarction, compared with $7 \%$ and $8 \%$ of the ischemic and primary arrhythmic event groups ( $p<0.05)$ (Table III).

Patients with a history of cardiac disease before cardiac arrest had a significantly worse cumulative survival rate $(\mathrm{p}<0.05)$ than those without previous cardiac disease (Fig. 2). The 1- and 2-year cumulative survival for the 36 patients without a history was $97 \%$ and $89 \%$ and that in the 191 patients with a history of cardiovascular disease was $76 \%$ and $61 \%$. The suddenness of cardiac arrest had no effect on cumulative mortality (Fig. 3).

The relation of symptomatic angina pectoris to the occurrence of symptoms before arrest is shown in Table IV. The prodromal symptoms of chest pain or indigestion occurred in approximately one-third of the patients. Its occurrence was similar in patients with and without a history of angina pectoris, although $28 \%$ of the patients without a history of angina pectoris had prodromal chest pain, compared to $37 \%$ with a history of angina pectoris (difference not significant).

\section{Discussion}

The sudden nature of death in CAD patients is supported by the examination of this very unique group of

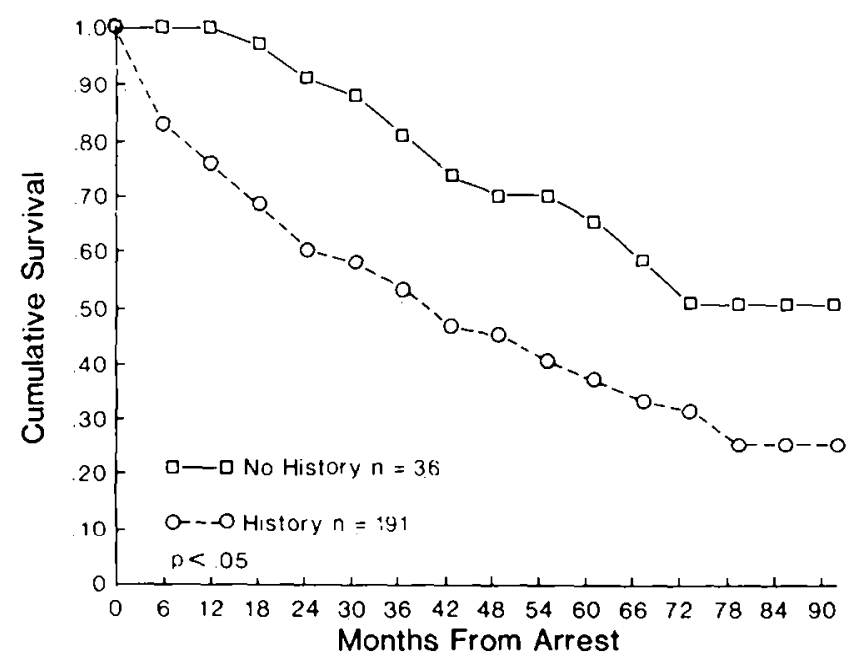

FIGURE 2. Cumulative survival of resuscitated out-of-hospital cardlac arrest victims related to history of cardiac history before arrest.
TABLE IV Prodromal Angina or Indigestion Related to Prior Angina Pectoris in Sudden Cardiac Arrest Patients

\begin{tabular}{lcccc}
\hline & & & Prodromal Symptoms \\
& $\begin{array}{c}\text { Chest Pain } \\
(\%)\end{array}$ & \multicolumn{2}{c}{$\begin{array}{c}\text { Chest Pain and/or } \\
\text { Indigestion } \\
(\%)\end{array}$} \\
\hline Angina pectoris & 0 & + & 0 & + \\
$0(n=67)$ & 72 & 28 & 67 & 33 \\
$+(n=76)$ & 63 & 37 & 59 & 41 \\
\hline
\end{tabular}

patients. However, $29 \%$ of these resuscitated out-ofhospital cardiac arrest victims do not fit the 1-hour definition of sudden death. This compares to epidemiologic studies of patients with CAD indicating that approximately $55 \%$ experience nonsudden death. ${ }^{5} \mathrm{Al}$ though our study patients usually had a history of cardiac disease, cardiac arrest occurred instantly and without symptoms in $26 \%$ of all patients. In the patients who died suddenly, cardiac arrest was the first expression of CAD in $5 \%$, and in $4 \%$ of all patients. In $85 \%$ of our patients, sudden cardiac arrest was preceded by a history of heart disease. In contrast, Doyle et $\mathrm{a}^{8}$ reported that $50 \%$ of the men and $70 \%$ of the women who died suddenly in the Albany-Framingham Study

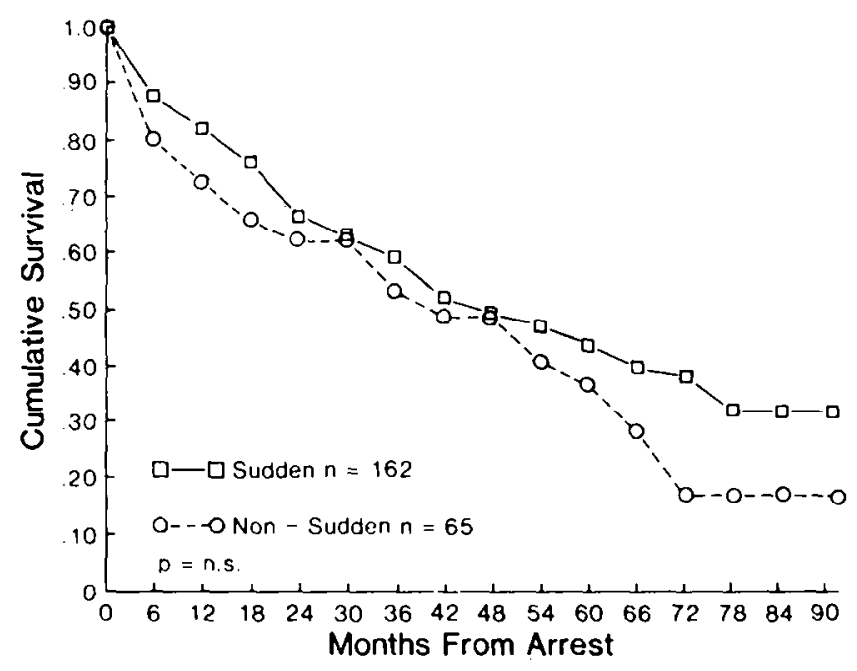

FIGURE 3. Cumulative survival of resuscitated out-of-hospital cardiac arrest victims related to sudden and nonsudden death. 
had no overt history of heart disease. They state that 1 of every 5 persons in whom CAD develops will present with sudden death as their first and only symptom. Our data do not support that conclusion.

The occurrence of significant events in CAD without symptoms was emphasized by Kannel and Abbott," who reported that $25 \%$ of the myocardial infarctions in patients in the Framingham study occurred without symptoms. Patients who had asymptomatic infarctions had a lower incidence of angina before that infarction. They proposed that patients who have a silent myocardial infarction previously demonstrate disassociation between pain and ischemia by their lack of prior angina pectoris. In the Framingham study the incidence of subsequent sudden death in the unrecognized or silent infarct group was $10 \%$ and in the recognized group $12 \%$. Deanfield et a ${ }^{10}$ correlated regional myocardial perfusion defects with ischemic ST-segment abnormalities occurring in the setting of mental stress. The occurrence of asymptomatic electrocardiographic manifestation of myocardial ischemia has been noted by several investigators. ${ }^{6,9-13}$. Schang and Pepine ${ }^{11}$ observed that only $25 \%$ of the episodes of significant ST-segment depression observed during 10-hour ambulatory monitoring were associated with symptoms. $\mathrm{Cohn}^{6}$ suggested that certain patients may actually be unable to develop pain as a response to ischemia and therefore may be at an increased risk of select ischemia and sudden death. Our study supports the concept that asymptomatic sudden cardiac arrest does occur, although the presence of chest pain before cardiac arrest was not related to the historical presence of angina pectoris.

Previous studies have suggested the instantaneous nature of sudden death. Goldstein et $\mathrm{al}$ (5) obscrved that death occurred instantaneously in $29 \%$ of 270 acute witnessed deaths in patients who had had a previous acute myocardial infarction and were enrolled in a secondary prevention trial of aspirin therapy. Chest pain occurred in $18 \%$ of the patients who had symptoms less than 1 hour before the event. A history of angina pectoris was recorded in $45 \%$ and $47 \%$ of those dying suddenly and nonsuddenly, respectively. In a study of resuscitated sudden death victims by Hall- strom and $\mathrm{Cobb},{ }^{3}$ angina pectoris and a prior myocardial infarction were reported in $40 \%$ of patients, hypertension in $38 \%$ and congestive heart failure in $18 \%$. These frequencies are similar to but somewhat less than those in our study.

The survival of cardiac arrest patients after out-ofhospital resuscitation in our study was not affected by the suddenness of death, but, as one would expect, was adversely affected by a history of cardiac disease. Similar observations were reported by Hallstrom and Cobb. ${ }^{3}$

This study supports the concept of the suddenness of death. Patients who have a cardiac arrest often have a history of cardiovascular disease and have symptoms before their arrest.

\section{References}

1. Goldstein S, Landis IR, Leighton R, Ritter G, Vasu CM, Wolfe RA, Acheson A, Medendorp SV. Predictive survival models for resuscitated victims of out of-hospital cardiac arrest with coronary heart disease. Circulation 1985 71:873-880.

2. Liberthson R, Nagel E, Hirschman I, Nussenfeld S. Prehospital ventricular defibrillation. $N$ Engl I Med 1974;291:317-321.

3. Hallstrom A, Cobb L. Predicting risk of recurrence in sudden cardiac death syndrome. Emergency Health Services Review 1984;2:49-61.

4. Madsen JK. Ischemic heart disease and prodromics of sudden cardiac death. Br Heart I 1985;54:27-32.

5. Goldstein S, Freidman L, Hutchinson R, Canner P, Romhilt D, Schlant R, Sabrino R, Verter J. Wasserman A, and the Aspirin Myocardial Infarction Study Research Group. Timing mechanism and clinical sctting of witnessed deaths in postmyocardial infarction patients. JACC 1984;3:1111-17.

6. Cohn PF. Silent myocardial ischemia in patients with a defective anginal warning system. Am I Cardinl 1.980;45:697-702.

7. Kannel W, Abbott R. Incidence and prognosis of unrecognized myocardial infarction: an update on the Framingham Study. N Engl T Med 1984;311:114447

8. Doyle JT, Kannel WB, McNamara PM, Quickenton P, Gordon T. Factors related to suddenness of coronary death: combined Albany-Framingham studies. Am I Cardiol 1976;37:1073-78

9. Haberern N, Khaja F, Barold SS. Case studies: significance of episodic painless ST segment elevation at rest in ischemic heart disease. I Electrocardiol 1975;8:173-77.

10. Deanfield JE, Shea M, Ribiero P, de Landsheere CM, Wilson RA, I Iorlock $\mathrm{P}$, Selwyn AP. Transient ST-segment depression as a marker of myocardial ischemia during daily life. Am I Cardiol 1984;54:1195-1200.

11. Shang S, Pepine C. Transient asymptomatic S-T segment depression during daily activity. Am I Cardiol 1977;39:396-401.

12. Stern S, Tzivoni D, Stern Z. Diagnostic accuracy of ambulatory ECG monitoring in ischemic heart disease. Circulation 1975;52:1045-49.

13. Stern S, Tzivoni D. Early detection of silent ischemic heart disease by $24-$ hour electrocardiographic monitoring of active subjects. Br Heart I 1974; $36: 481-86$. 